\title{
AS CONSEQUÊNCIAS DA COVID-19 PARA A PRÁTICA ESPORTIVA DA POPULAÇÃO: UM RELATO DE EXPERIÊNCIA
}

\begin{abstract}
Yara de Oliveira Pena ${ }^{1}$, ORCID ID 0000-0001-9038-1940; Nícolas Emanuel Oliveira Reis ${ }^{1}$, ORCID ID 0000-00018098-801X ; Fernanda Lima Marçal' ${ }^{1}$, ORCID ID 0000-0003-0257-6460 ; Ana Flávia Gamarano Moreira1 , ORCID ID 0000-0001-5879-2408; Davi Nilson Aguiar e Moura1 , ORCID ID 0000-0002-8960-7540; Milena de Oliveira Simões², ORCID ID 0000-0002-1088-7456
\end{abstract}

\section{FILIAÇÃO}

(1) Universidade Federal de Juiz de Fora campus Governador Valadares, Medical Student.

(2) Universidade Federal de Juiz de Fora campus Governador Valadares, Doutora, Professora do Departamento de Medicina.

\section{AUTOR CORRESPONDENTE}

Yara de Oliveira Pena; yaraoliveirapena@gmail.com; Avenida Rio Doce, 1020, casa, São Pedro. Governador Valadares - Minas Gerais.;CEP: 35020-490; Universidade Federal de Juiz de Fora campus Governador Valadares.

\section{MENSAGENS-CHAVE}

Hábitos saudáveis garantem o fortalecimento do sistema imunológico, o que contribui para reduzir o nível de gravidade pela progressão da COVID-19.

Treinos de atletas profissionais contribuem para o enfraquecimento imunológico e o consequente maior risco de desenvolvimento da condição patológica.

No contexto de pandemia, o exercício físico torna-se mais necessário para a prevenção de doenças cardiovasculares e mentais, bem como do sedentarismo.

O retorno gradual é importante (atenção à abrangência dos riscos e às implicações) para evitar desgaste do atleta e complicações cardíacas.

Esportistas devem seguir recomendações da Sociedade Brasileira de Medicina do Exercício e do Esporte a fim de assegurar o retorno saudável à atividade.

\section{RESUMO}

INTRODUÇÃO: É notório que as atividades físicas apresentam inúmeros benefícios para a saúde dos indivíduos, inclusive para o sistema imune. Contudo, existem importantes particularidades da prática em questão no que tange à contaminação por COVID-19, visto que o exercício físico mal orientado e/ou a sobrecarga dele podem ser prejudiciais ao bem-estar dos indivíduos, afetando negativamente a imunidade e a integridade da saúde, principalmente no período pós-infecção. Nesse sentido, o atual estudo objetiva relatar o evento "As consequências da COVID-19 para a prática esportiva da população", que visou transmitir informação e incentivar a reflexão pela sociedade, em especial os estudantes e os praticantes de atividades físicas. RELATO: As palestras ocorreram via Google Meet $\Theta$, contando com a presença de dois médicos, sendo um especialista em Medicina da Família e Comunidade e o outro em Medicina Esportiva. Os palestrantes discorreram sobre o assunto e elucidaram as dúvidas relatadas pelos participantes, as quais foram advindas de um questionário aberto no momento da inscrição e do chat durante a realização das palestras. Para avaliação da atividade realizada, foram feitas perguntas pessoais e temáticas no formulário de inscrição e de checkout. DISCUSSÃO: A discussão proposta foi considerada de grande valor pelos ouvintes. De um lado, foi esclarecido que, mesmo em tempos de pandemia, é recomendado que as pessoas realizem exercícios regularmente, em intensidade moderada. Por outro lado, certos cuidados são necessários em relação ao indivíduo que adquiriu COVID-19, uma vez que seu condicionamento físico pode ter sido drasticamente reduzido. CONCLUSÃO: Os conhecimentos disseminados pelos palestrantes referentes ao exercício físico associado à COVID-19 propiciaram a reflexão dos ouvintes no que concerne às práticas esportivas saudáveis e possibilitaram que estes se tornassem 
fontes de multiplicação de informações confiáveis, apoiadas no embasamento científico compartilhado por profissionais aptos a discorrerem acerca da temática.

\section{PALAVRAS-CHAVE: Coronavírus; Exercício Físico; Estilo de Vida Saudável.}

\section{ABSTRACT}

INTRODUCTION: It is notorious that physical activities have numerous benefits for the health of individuals, including the immune system. However, there are important particularities of the practice in question regarding the contamination by COVID19 , since the misguided physical exercise and/or its overload can be harmful to the well-being of individuals, negatively affecting the immunity and the integrity of health, especially in the post-infection period. In this sense, the current study objectifies to report the event "The consequences of COVID-19 for the sporting practice of the population", which aimed to convey information and encourage reflection by society, especially students and practitioners of physical activities. REPORT: The event occurred via Google Meet ${ }^{\circledR}$, with the presence of two physicians, one being a specialist in Family and Community Medicine and the other one in Sports Medicine. The lecturers talked about the subject and clarified the doubts reported by the participants, which came from an open questionnaire at the time of registration and chat during the presentations. To evaluate the activity, personal and thematic questions were asked in the registration and checkout forms. DISCUSSION: The proposed discussion was considered of great value by the listeners. On one hand, it was clarified that, even in times of pandemic, it is recommended that people exercise regularly, at moderate intensity. On the other hand, certain precautions are necessary regarding the individual who has acquired COVID-19, since his physical conditioning may have been drastically reduced. CONCLUSION: The knowledge disseminated by the speakers about the physical exercise associated with COVID-19 allowed the listeners to reflect on healthy sports practices and made it possible for them to become sources for the multiplication of reliable information, supported by scientific basis shared by professionals able to discuss the theme.

\section{KEYWORDS: Coronavirus; Exercise; Healthy Lifestyle.}

\section{INTRODUÇÃO}

Em dezembro de 2019, descobriu-se um vírus responsável por causar infecções respiratórias em Wuhan, na China, que despertou atenção internacional pela sua facilidade de contágio e pela capacidade de disseminar formas graves de manifestação da doença que, atualmente, é conhecida como COVID-19. As infecções causadas pelo vírus, posteriormente denominado SARS-CoV-2, incluíam além do mal estar, febre, tosse seca e dispneia ${ }^{1}$.

$\mathrm{Na}$ tentativa de traçar um perfil epidemiológico dos acometidos, notou-se que, entre os idosos e os indivíduos com doenças crônicas associadas, havia uma maior tendência de desenvolver a forma grave da doença ${ }^{2}$. Nesse sentido, jovens saudáveis, sobretudo atletas, poderiam ser um grupo de baixo risco para a patologia. Contudo, essa afirmação pode não ser completamente verdadeira, uma vez que alguns estudos demonstram que atletas estão mais propensos às infecções do trato respiratório superior. Ademais, comumente os atletas se expõem aos treinos de alta intensidade e volume (carga do treino) para alcançar desempenhos esportivos melhores, 0 que pode comprometer o sistema imunológico e torná-los um grupo de risco ${ }^{3}$.

A prática de exercícios físicos deve ser incentivada. No entanto, durante a pandemia da COVID-19, é necessário que alguns cuidados sejam tomados para que o exercício físico desorientado e/ou de alta intensidade não se torne um empecilho, principalmente no desenvolvimento de janelas de imunossupressão. Além disso, a retomada das atividades após a infecção deve ser lenta e gradual, para que problemas como miocardites não ocorram ${ }^{3}$.

É válido ressaltar que o profissional médico precisa estar apto a orientar seus pacientes quanto à prática de exercícios em casos de acometimento por infecção viral respiratória, bem como em situações em que o ambiente da prática dos exercícios torna os praticantes vulneráveis. Por esse motivo, o atual estudo objetiva relatar a mesa redonda, intitulada "As consequências da COVID-19 para a prática esportiva da população", que visou transmitir informação e incentivar a reflexão pela população, em especial os estudantes e os praticantes de atividades físicas, acerca das consequências da COVID-19 para a prática esportiva.

\section{RELATO DE EXPERIÊNCIA}

A mesa redonda intitulada "As consequências da COVID-19 para a prática esportiva da população" foi realizada de forma virtual no dia 26 de fevereiro de 2021, contando com 83 inscrições. A divulgação ocorreu por meio das redes sociais, tais como o Instagram $\AA$ do comitê local, grupos do Whats $A p p \AA$ e grupos de divulgação de eventos do Telegram $\AA$, a partir do dia 22 de fevereiro de 2021 até o dia do evento. Este aconteceu por meio da plataforma online Google Meet $\AA$, devido à quantidade de inscritos.

Juntamente à inscrição do evento, realizada por meio da plataforma Google Formulários $\AA$, foram acrescentadas quatro perguntas sobre a temática a fim de detectar os conhecimentos prévios na área, bem como se a pessoa possuía alguma dúvida a ser sanada durante a palestra. As perguntas realizadas foram: "Você considera a prática de atividades físicas algo indispensável?", "Você acha que uma pessoa que contraiu a COVID-19 deve continuar praticando exercícios físicos normalmente?", "O quão importante você considera entender as implicações da COVID-19 na prática de exercícios físicos?", e "Como você define seu grau de conhecimento a respeito do tema?". As respostas foram elucidadas ao longo do evento e, ao final, foram enviadas as 
mesmas perguntas no formulário de check out, elaborado também na plataforma Google Formulários ${ }^{\circledR}$, a fim de avaliar o impacto e a efetividade da ação.

A mesa redonda contou com a participação de dois profissionais da saúde com experiência nas temáticas abordadas. Cada palestrante teve a oportunidade de discorrer sobre o assunto, sendo que, imediatamente após a explanação de cada um, foram realizadas perguntas referentes à apresentação. A primeira palestra foi realizada por um médico da família e teve duração de 1 hora, expondo a importância da prática do exercício físico para a prevenção de doenças cardiovasculares e do sedentarismo, principalmente durante o contexto de pandemia em que estamos inseridos. Já a segunda foi realizada por um médico do esporte, que dissertou acerca dos cuidados que devem ser tomados por pessoas ativas que contraírem a COVID-19, do prognóstico e das recomendações sanitárias para a prática de exercícios, com a duração da palestra também sendo de 1 hora.

Deve-se apontar, entretanto, que o tempo não foi suficiente para que os palestrantes colocassem em pauta todo o conhecimento que possuíam. Alguns relatos e comentários foram realizados de forma mais rápida e sucinta para que o tempo planejado fosse respeitado. Contudo, devido ao formato online do evento, o público atingido foi maior do que o esperado, contemplando a presença de estudantes de outros cursos de graduação e de outras universidades, bem como a participação de um palestrante que pertencia a outro estado brasileiro. Ademais, a abordagem de um tema tão atual e presente no meio social foi positiva e agregou valor ao evento.

\section{DISCUSSÃO}

As palestras elucidaram de forma ampla a relação da COVID-19 com a prática esportiva, compreendendo os pontos essenciais acerca dessa temática. Nesse sentido, foi destacado que a prática de exercícios físicos estimula a atividade imune, tornando os indivíduos menos suscetíveis a agentes patológicos, especialmente os de infecções respiratórias ${ }^{4}$. Dessa forma, uma vida fisicamente ativa se revela uma medida de baixo custo e com alto potencial benéfico, principalmente no contexto atual de pandemia, visto que pode ser um modo de promoção de saúde e prevenção contra agravos decorrentes de uma possível infecção pelo novo coronavírus ${ }^{4}$. Logo, recomenda-se que, mesmo em período de pandemia, as pessoas realizem exercícios regularmente, em intensidade moderada. É válido destacar que tal indicação é reforçada principalmente à população idosa, que geralmente apresenta comorbidades, as quais tornam o sedentarismo um risco ainda maior à saúde 5 .

Por outro lado, um indivíduo que adquiriu COVID-19 precisa ter certos cuidados, uma vez que o seu condicionamento físico pode ter sido drasticamente reduzido ${ }^{6}$. Nota-se que, após uma infecção pelo SARS-CoV-2, o paciente pode desenvolver lesões cardíacas, incluindo miocardite viral, além de complicações tromboembólicas ${ }^{7}$.
Além dos reais benefícios da prática de atividades físicas na prevenção contra o desenvolvimento de doenças provenientes do sedentarismo, e até de ordem mental ${ }^{8}$, foi abordada, no evento, a questão do retorno à realização de exercícios após a recuperação de um paciente com COVID-19. Observa-se que, após a infecção, um indivíduo pode sofrer com as complicações da doença durante um longo período de tempo, o que prejudica sua função física ${ }^{6}$. Assim, é recomendado que o paciente, com sorologia positiva, apenas retorne à prática física após um período sem manifestar sintomas, e, ainda, mantendo uma progressão gradual na intensidade, destacando-se que cada caso deve ser avaliado individualmente ${ }^{9}$.

\section{CONCLUSÃO}

A atividade proposta foi realizada com êxito. A discussão realizada pelos profissionais foi de extrema importância para o desenvolvimento do tema "As consequências da COVID-19 para a prática esportiva da população". Além de incitarem a reflexão sobre o tema principal, os palestrantes fizeram uma abordagem geral acerca da atividade física, bem como sugestões para a sua prática saudável, propiciando que os ouvintes se tornassem multiplicadores de informações confiáveis e embasadas cientificamente.

Por fim, nota-se que a temática da atividade é de grande relevância, uma vez que versa sobre um tema atual e que afeta diretamente a saúde da população no cotidiano. Logo, fazem-se necessários mais eventos e discussões sobre a COVID-19 no contexto da prática de exercícios físicos, de modo que os indivíduos possam estar cada vez mais esclarecidos, saudáveis e cientes de seus direitos e deveres enquanto cidadãos.

\section{CONFLITO DE INTERESSE}

Autores declaram que não houve conflito de interesse.

\section{FINANCIAMENTO}

Autores declaram que não houve fonte de financiamento.

\section{REFERÊNCIAS}

1. Huang C, Wang Y, Li X, Ren L, Zhao J, Hu Y, et al. Clinical features of patients infected with 2019 novel coronavirus in Wuhan, China. The Lancet. 2020 Feb;395(10223):497-506. Disponível em: https://www.thelancet.com/journals/lancet/article/PIIS01406736(20)30183-5/fulltext

2. Chen N, Zhou M, Dong X, Qu J, Gong F, Han Y, et al. Epidemiological and clinical characteristics of 99 cases of 2019 novel coronavirus pneumonia in Wuhan, China: a descriptive study. The Lancet. 2020 Feb;395(10223):507513. Disponível em: https://www.thelancet.com/journals/lancet/article/PIIS01406736(20)30211-7/fulltext 
3. Guerreiro RC, Silva A, Andrade HA, Biasibetti IG, Vital R, Silva Hesojy GV, et al. O adiamento dos jogos olímpicos e paralímpicos de Tóquio 2020 foi uma decisão correta. Rev Bras Med Esporte. 2020 Jun; 26(3), 191-195. Disponível em:

https://www.scielo.br/scielo.php?script=sci_abstract\&pid=S 1517-

$86922020000300191 \&$ Ing=en\&nrm=iso\&tlng=pt\#: :text=N esse\%20sentido\%2C\%20a\%20tomada\%20de,paral\%C3\% ADmpicos\%2C\%20bem\%20como\%20dos\%20expectador es.

4. Alkhatib A. Antiviral Functional Foods and Exercise Lifestyle Prevention of Coronavirus. Nutrients. 2020 Aug;12(9):2633. Disponível em: https://pubmed.ncbi.nlm.nih.gov/32872374/

5. da Silveira MP, da Silva Fagundes KK, Bizuti MR, Starck É, Rossi RC, de Resende E Silva DT. Physical exercise as a tool to help the immune system against COVID-19: an integrative review of the current literature. Clin Exp Med. 2021 Feb;21(1):15-28. Disponível em: https://pubmed.ncbi.nlm.nih.gov/32728975/

6. Rooney S, Webster A, Paul L. Systematic Review of Changes and Recovery in Physical Function and Fitness After Severe Acute Respiratory Syndrome-Related Coronavirus Infection: Implications for COVID-19 Rehabilitation. Phys Ther. 2020 Sep;100(10):1717-1729. Disponível em: https://pubmed.ncbi.nlm.nih.gov/32737507/

7. Salman D, Vishnubala $D$, Le Feuvre $P$, Beaney $T$, Korgaonkar J, Majeed A, McGregor AH. Returning to physical activity after covid-19. BMJ. 2021 Jan;372:m4721. Disponivel em: https://www.bmj.com/content/372/bmj.m4721

8. Jiménez-Pavón D, Carbonell-Baeza A, Lavie CJ. Physical exercise as therapy to fight against the mental and physical consequences of COVID-19 quarantine: Special focus in older people. Prog Cardiovasc Dis. 2020 MayJun;63(3):386-388. Disponível em: https://www.ncbi.nlm.nih.gov/pmc/articles/PMC7118448/

9. Yeo TJ. Sport and exercise during and beyond the COVID19 pandemic. Eur J Prev Cardiol. 2020 Aug;27(12):1239$1241 . \quad$ Disponível em: https://journals.sagepub.com/doi/full/10.1177/2047487320 933260 